\title{
INFLAÇÃO E PACTO SOCIAL NO BRASIL E NO MÉXICO
}

\author{
IAN ROXBOROUGH*
}

\author{
A POLÍTICA DA INFLAÇĀO NA AMÉRICA LATINA
}

Nos últimos anos a inflação acelerou-se na América Latina, tornando-se um problema aparentemente insolúvel. Em muitos países, mesmo quando níveis elevados de inflação ou hiperinflação foram controlados, o "piso" inflacionário permaneceu elevado, com toda a aparência de terreno com patamares ascendentes e irreversíveis. A inflação anual média continuou a crescer constantemente, como pode ser visto na tabela 1.

As razões para a persistência da inflação alta e a aparente incapacidade das políticas governamentais de reduzi-la de maneira duradoura são complexas e alvo de controvérsias. Ademais, como vários autores salientaram ${ }^{1}$, as razões para o fracasso das políticas antiinflacionárias são, em certa medida, políticas, ademais de puramente econômicas.

Por um lado, a inflação e os esforços para controlá-la envolvem um conflito redistributivo cujos custos políticos o governo pode não ser capaz de assumir ou não querer fazê-lo. Além disso, o governo pode simplesmente não ter capacidade administrativa de implementar efetivamente algumas medidas. Por exemplo, uma maneira de restabelecer o equilíbrio fiscal é. aumentar

\footnotetext{
* Tradução de Anna Volochko.

$1_{R}$. Dornbusch e S. Edwards "La Macroeconomía del populismo en América Latina", El Trimestre Económico, n² 225, enero-marzo, 1990.
} 


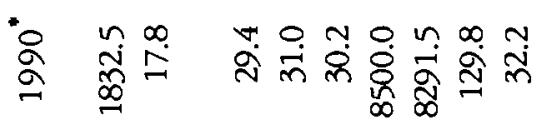

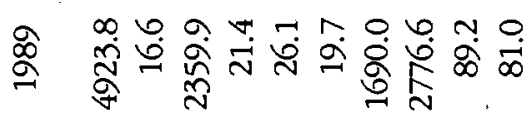

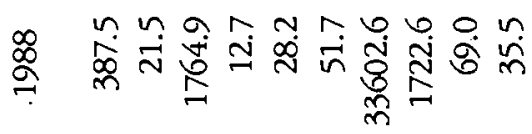

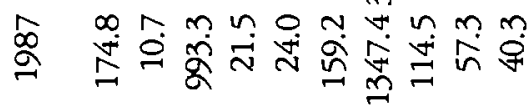

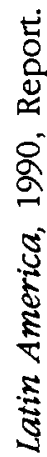

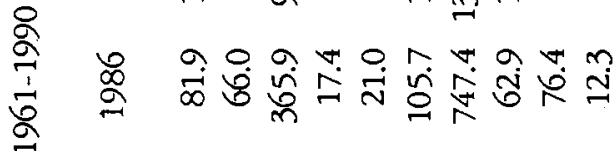

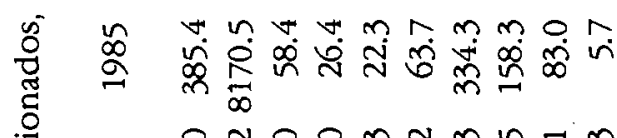

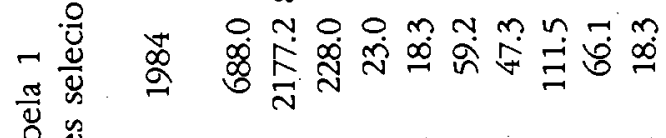

章

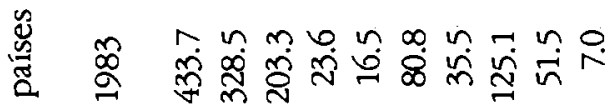

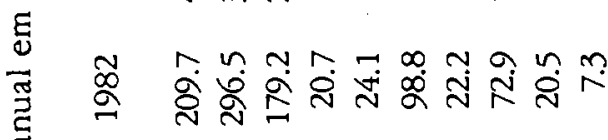

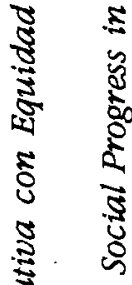

惢

市

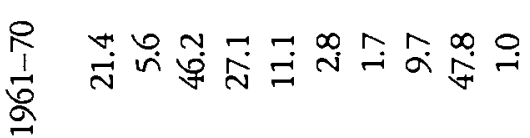

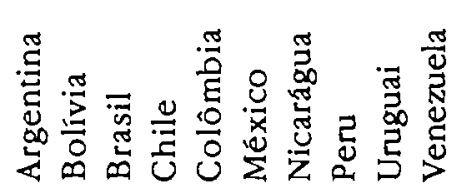


impostos sobre os detentores de riqueza, mas essa pode não ser uma opção politicamente factível para muitos governos. Governos centrais podem ter controle limitado sobre os gastos dos governos regionais e locais ou das empresas estatais, e ter portanto dificuldade em controlar a despesa.

Além disso, políticas antiinflacionárias efetivas nẹcessitam de condições políticas que simplesmente não existem em muitos sistemas políticos latino-americanos.

Por exemplo, em setembro de 1989 , no fim do governo Sarney, a inflação era de $38 \%$ por mês. O ministro da Fazenda, Mailson da Nóbrega, admitiu publicamente que o governo não dispunha de meios para controlar a inflação.

Não apenas existem componentes políticos na causação e no controle da inflação como também longos períodos inflacionários trazem conseqüências políticas, além das econômicas. A inflação pode levar à redução do crescimento econômico ao reduzir os horizontes temporais, aumentando o risco de potenciais investidores e provocando uma queda na taxa de investimento. A inflaçào também pode ter sérias conseqüências na distribuição de renda, transferindo-a de agentes com renda fixa ou rendas infreqüentemente reajustadas para agentes que operam com preços totalmente flexíveis.

Além de gerar intensa luta redistributiva ${ }^{2}$, a inflação pode também produzir profundo e amplo desencanto com o governo e as elites políticas em geral, percebidas como incompetentes na administração da economia.

Para países que se redemocratizaram recentemente, como o Brasil e a Argentina, o contínuo fracassso em controlar a inflação levanta questōes sobre a progressão contínua no caminho da democracia. ${ }^{3}$

No México, o problema político é um tanto diferente. Desde a revolução de 1910 o México tem sido governado por um único partido político, o Partido Revolucionario Institucional

\footnotetext{
${ }^{2}$ C. Maier, em seu Recasting Bourgeois Europe, Princeton, Princeton University Press, 1975, relata os conflitos gerados pela inflação na Europa no periodo pós-I Guerra Mundial e a incapacidade das instituiçōes de canalizá-los adequadamente, culminando com ampla deterioração política. Numerosos autores apontaram os conflitos distributivos associados com a inflação na América Latina.

3 Por democracia entendo aqui um sistema político no qual os postos mais altos são preenchidos por eleiçōes livres e justas que envolvem amplo direito de voto. A noção de eleições "livres e justas" implica um conjunto de pré-condif̧ōes ta is como uma imprensa livre, liberdade de associação e a vigência do império da lei.
} 
$(\mathrm{PRI})^{4}$ que "venceu" todas as eleiçōes presidenciais até hoje. Apesar de considerável abertura política em anos recentes, o PRI continua a monopolizar o poder político e provavelmente deve sua posição à manipulação eleitoral. ${ }^{5}$ Nessas circunstâncias, o fracasso no controle da inflação levanta questôes sobre a estabilidade política do México e sobre a progressão contínua no caminho da abertura política. ${ }^{6}$

Em toda a América Latina, os esforços para o controle da inflação repercutiram profundamente no sistema político da região. Em alguns casos o resultado foi a fragmentação do já débil sistema de partidos (Brasil, por exemplo) e a emergência de candidatos anti-sistema, com considerável apoio popular (Peru, Brasil). Em diversos países presidentes têm sido eleitos a partir de promessas de minorar o fardo das camadas mais pobres da comunidade, e uma vez empossados, têm implementado políticas que têm resultado na deterioração ainda maior do padrão de vida (Andres Pérez - Venezuela, Carlos Menem Argentina, Alberto Fujimori - Peru, e Fernando Collor de Mello Brasil). Em alguns desses países as medidas de austeridade impostas pelo governo desencadearam revoltas e pilhagens de supermercados, levando comentaristas a questionar a estabilidade política e a governabilidade desses países. Mesmo que os temores sejam exagerados, o fato de muitos líderes populares "terem traído" seu eleitorado levanta dúvidas sobre a solidez institucional do sistema de partidos desses países.

A credibilidade dos governos e a popularidade dos presidentes foi se volatilizando à medida que a economia da América Latina seguiu a rota da inflação. É possível especular que, com o crescente enfraquecimento dos partidos, os sistemas políticos tenham sido progressivamente invadidos por interesses organizados, especialmente empresariais, em uma tentativa de exercer pressão direta na formulação de políticas. ${ }^{7}$ É evidente que o papel das empresas na formulação de políticas públicas na

${ }^{4}$ Conhecido anteriormente como PRM e PNR.

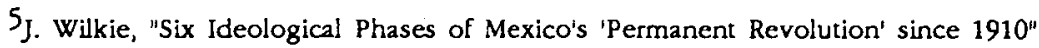
in J. Wilkie (ed.), Society and Economy in Mexico, Los Angeles, UCLA publications, p. 50, 1990, argumenta que o PRD provavelmente ganhou as eleições presidencia is de 1988.

${ }{ }_{\text {A }}$ questão de se saber se o México caminha para a democracia está, atualmente, em aberto.

7D. Garcia, "Democracia y ajuste estructural", Argumenlos, 7, Agosto, 1989. 
América Latina sempre foi importante, mas no passado sua participação foi mediada por instituições corporativas. Podemos estar testemunhando agora formas mais diretas de penetração e, nesse caso, outro elemento de retorno à política pretoriana. ${ }^{8}$

\section{DIAGNÓSTICOS DE INFLAÇÃO}

Embora o estudo da inflação continue a gerar considerável controvérsia, é possível identificar quatro fatores principais na produção de inflação: (1) inflação importada; (2) déficits fiscais; (3) ineficiência e distorçōes de mercado; e (4) inércia. Em qualquer caso específico a inflação pode ser o resultado da combinação, em proporções variáveis, de alguns ou todos os componentes mencionados acima. Políticas antiinflacionárias adequadas devem atacar todos os componentes relevantes simultaneamente. Neste artigo, limito-me à análise da inflação inercial.

Existem três abordagens principais relativas à inflação inercial: eliminação dos mecanismos de propagação, medidas de choque e pacto social. A grande parte da discussão sobre mecanismos de propagação (tais como indexação) trata dos sintomas em vez da própria doença. Embora o enfraquecimento dos mecanismos de propagação possa ser útil, eles não atuam diretamente nas expectativas ou nas estratégias de defesa adotadas pelos atores para realocar os custos do ajuste.

O tratamento de choque raramente será eficaz, a menos que se acompanhe por mudanças institucionais substantivas; entretanto, na maioria dos programas heterodoxos o choque tem sido usado como substituto das mudanças institucionais. Assim nos restam os pactos sociais, notoriamente difíceis de serem alcançados. Por que isso acontece ?

$8^{O}$ termo vem de Samuel Huntington, Political Order in Changing Societies. Refere-se a dificuldade de criar instituiçōes políticas numa sociedade em rápida transformação. 


\section{POR QUE OS PACTOS SOCIAIS SÃO DIFÍCEIS DE SEREM ACORDADOS ?}

As dificuldades inerentes de persuadir sindicatos e empresários em participar do pacto social são sugestivamente ilustradas quando o analisamos em termos do Dilema do Prisioneiro. ${ }^{9}$ Suponhamos que os jogadores são os sindicatos e os empresários. (O governo será incorporado à análise mais tarde). Assumamos que para ambos o resultado da cooperação seja a redução da inflação que proporcionará um aumento do poder aquisitivo real para os trabalhadores e um aumento da demanda (e portanto dos lucros) para os empresários. Os sindicatos serão "trouxas" se concordarem com controle de salários em um momento em que os preços continuem a subir; por outro lado, os empresários serão "trouxas" se controlarem o preço em uma situação onde um mercado de trabalho rígido (ou intervenção governamental) permita aos sindicatos altas reais de salários rápidas o suficiente para ameaçar as margens de lucro. Finalmente, a solução, sub-ótima e estável, é aquela em que sindicatos e empresários não cooperam e onde, em conseqüência, os salários reais estão erodidos pela inflação contínua e os lucros pela estagnação econômica.

Em todos os jogos do Dilema do Prisioneiro, a estrutura de ganhos determina os incentivos para cooperar ou desertar. Como Axelrod argumentou, em interaçōes repetidas as estratégias "olho por olho, dente por dente" (de pagar na mesma moeda) geralmente resultam na solução ótima. ${ }^{10}$ Para se aplicar o Dilema

9 Dilema do Prisioneiro é assim denominado devido à seguinte história. A polícia prendeu dois bandidos e está ceña de que cometeram um crime mas nâo possui provas. Colocam cada prisioneiro em urna solitária e oferecem-lhes um trato caso confessem. O prisioneiro que confessar terá uma pena leve e o outro uma sentença pesada. Nesta situação, se cada prisioneiro confiar no outro, ambos permanecerão calados e serão libenados. Esta é a situação btima. Requer que cada prisioneiro coopere com o outro. Mas outros resultados podem acontecer. Cada um pode ser tentado, se não confiar inteiramente no outro, a "trair" seu colega, que será o "trouxa" ("sucker"). Ademais, face a essa possibilidade, ambos podem decidir delatar o outro. Nessa situação a polícia não tem mais incentivo em recompensar o delator e é provável que ambos recebam penas substanciais, embora não tão pesadas quanto se eles forem "trouxas". A estrutura de resultados pode ser esquematizada como se segue. Os valores numéricos associados a cada resultado desse exemplo são arbitrários.

$10_{\mathrm{R}}$. Axelrod, The evolution of Cooperation, London, Penguin, 1984. 
do Prisioneiro à situação inflacionária da América Latina, hă entretanto algumas qualificaçōes a serem levadas em consideração.

Figura 1. O Dilema do Prisioneiro

\begin{tabular}{|c|c|c|c|}
\hline \multicolumn{4}{|c|}{ Jogador I (coluna) } \\
\hline \begin{tabular}{|l|}
$J$ \\
$O$ \\
$G$ \\
A \\
$\mathbf{D}$ \\
$\mathbf{O}$ \\
$\mathbf{R}$ \\
\\
$\mathbf{I I}$ \\
(li- \\
nha)
\end{tabular} & Coopera & $\begin{array}{c}\text { Coopera } \\
\mathrm{P}=3, \mathrm{P}=3 \\
\text { Prêmio para } \\
\text { cooperação mútua } \\
\mathrm{T}=5, \mathrm{PT}=0 \\
\text { Tentação de desertar e } \\
\text { prêmio do "trouxa" }\end{array}$ & $\begin{array}{c}\text { Deserta } \\
\text { PT }=0, \mathrm{~T}=5 \\
\text { Prêmio do "trouxa" e } \\
\text { tentação de desertar } \\
\qquad \begin{array}{c}\mathrm{P}=1, \mathrm{P}=1 \\
\text { Punição }\end{array} \\
\text { para deserção mútua }\end{array}$ \\
\hline
\end{tabular}

De fato, as dificuldades de se chegar a uma solução ótima no contexto latino-americano são tão grandes que William Smith argumentou, baseado no estudo do plano Cruzado no Brasil e do plano Austral na Argentina, que, embora "teoricamente todos os setores e grupos ganhassem mais se se engajassem em uma 'luta de classe democrática'... no contexto latinoamericano essa descrição das virtudes dos pactos sociais parece um tanto utópica." ${ }^{11}$ Ele observa que o pacto social é particularmente sedutor quando a institucionalização do conflito político é pequena. Mas é exatamente essa baixa institucionalização que torna dificil o preenchimento das condições, bastante exigentes,

11W. Smith, "Heterodox Shocks and the Political Economy of Democratic Transition in Argentina and Brazil" in W. Canak (ed), Lost Promises: Debt, Austerity and Development in Latin America, Boulder, Westview, p. 151, 1989. 
de sucesso do pacto social. De acordo com Smith estas condições são as seguintes:

"...a concertación necessita que os atores sociais relevantes aceitem como legítimos o governo e o regime. Em segundo lugar, deve haver uma razoável convergência das estratégias globais adotadas pelo trabalho, pelo capital e pelo Estado. Em terceiro... trabalho e capital devem concordar sobre uma agenda mínima e é necessário que haja incentivos claros para os resultados mutuamente satisfatórios. Quarto, o Estado 'deve ceder parte de seu poder de decisão' sobre política econômica em favor das organizações de trabalhadores e das associações que representem os interesses empresariais, atribuindo, destarte, status público a interesses privados. Finalmente,... os empresários e os trabalhadores devem 'oferecer ao Estado seu poder político, garantindo o consenso e mobilizando seus próprios recursos para assegurar a legitimação, eficiência e eficácia da ação estatal'."12

Concretamente, Smith sublinha as divisões tanto no campo do trabalho quanto no do capital, a ausência de confiança entre atores, as tentativas generalizadas de pegar "caronas", as orientaçōes tecnocráticas dos governos brasileiro e argentino e as estratégias de confronto adotadas por segmentos importantes do movimento trabalhista de cada país. A análise de Smith sobre a situação do Brasil e da Argentina é bastante interessante. ${ }^{13}$

Dado o aparente sucesso do pacto social mexicano vale a pena reexaminar suas características para descobrir por que os mexicanos foram bem-sucedidos, buscando possíveis lições aplicáveis a outros países latinos. Meu argumento é que a questão chave $\hat{e}$ o desenvolvimento de instituições de natureza corporativa dentro de um contexto político específico cuja melhor

12 W. Smith, op cit., p. 152. Os trechos citados por Smith são de E. de Riz et al, "El contexto y los dilemas de la concertación en Argentina actual" in M. dos Santos (ed), Concertación Politico-Social y Democratización, Buenos Aires, CLACSO, 1987.

$13_{\mathrm{E}}$ não é totalmente diferente da posição desenvolvida independentemente por mim em "Organized Labor: a Major Victim of the Debt Crisis" in B. Stallings and R. Kaufman (eds), Debt and Demacracy in Latin America, Boulder, Westview, 1989. 
descrição é "social-democracia". Examino inicialmente a questão em termos teóricos gerais introduzindo a seguir uma complicação derivada da necessidade de jogar um jogo simultâneo com atores econômicos internacionais.

A primeira observação é a de que o jogo não é jogado com freqüência suficiente para gerar alta probabilidade de soluções estáveis ótimas. A maioria das abordagens teóricas do jogo assume que um grande número de interaçōes levará à solução estável. Isso entretanto não é provável. Geralmente são necessários vários meses para que os resultados de uma política fiquem evidentes, e é possível apenas um número limitado de tentativas durante certo intervalo de tempo. Conseqüentemente, para se chegar à solução ótima, cada ator deve escolhê-la no seu primeiro movimento ou logo no início do jogo. A questão essencial, portanto, passa a ser uma questão de confiança (ou de falta de alternativa). Para um sociólogo isso significa investigar as condições que favorecem a confiança entre as partes. Voltarei a esse ponto posteriormente.

Outro aspecto a ser considerado diz respeito à informação imperfeita. No jogo assume-se que cada ator sabe - como o outro jogou na rodada anterior. Na vida real as coisas são mais complexas. Cada ator deve interpretar o comportamento dos demais. As ações estão geralmente abertas a uma variada gama de interpretações. A informação não pode ser perfeita; isso pode dar margem a interpretações equivocadas das intenções, podendo levar a longas espirais de desentendimento mútúo.

Em terceiro lugar, deve-se questionar a premissa de que tratamos com agentes unitários ou homogêneos. As categorias designadas como "sindicatos", "empresários" e "governo" são, na verdade, constelações de grande número de organizações e indivíduos, cada qual com interesses, estratégias e interpretações bastante diversas. Tipicamente, os governos tendem a se dividir entre ministérios da área econômica e do trabalho, e entre tecnocratas e políticos. Como diz William Smith:

"A prontidão com que Sarney recorria ao uso das leis antitrabalhistas draconianas negava o discurso oficial sobre sua boa vontade na obtenção do pacto social, res- 
saltando a persistência de modos tecnoburocráticos de se fazer políticas públicas, herdadas do autoritarismo." 14

Os sindicatos estão quase sempre divididos entre os proponentes de estratégias de confronto (deserção) e os de estratégias de cooperação. As associações de empresários estão igualmente divididas sobre questões estratégicas. Podem haver divisões entre produtores de bens de exportação e os que se dedicam principalmente ao mercado interno; haverá embates setoriais e divergências entre pequenos e grandes empresários. Como essas divergências virtuais entre grupos empresariais funcionam na prática dependerá das formas concretas de organização de determinada sociedade. ${ }^{15}$

Quão grave é essa objeção de que não lidamos com atores unitários ? Em algumas circunstâncias os sindicatos, associações de empresários ou governo agem com razoável unanimidade. Outras vezes, eles estâo muito fragmentados. Essa é uma questão essencialmente empírica e variará de situação para situação.

Até aqui discuti o Dilema do Prisioneiro como um jogo envolvendo dois jogadores. Se se assumir um modelo que englobe 3 ou mais jogadores, uma série de modificações deverá ser feita. Aumentado o número de jogadores, para incluir o governo ou outros atores, duas coisas acontecem. Primeiro, se uma situação estável requer cooperação por parte de todos os jogadores, o número de soluçōes estáveis, proporção do número total de soluções possíveis, diminui. A probabilidade de se alcançar solução estável ótima deve, portanto, diminuir. Em segundo lugar, com vários jogadores existe a possibilidade de formar coalizōes. Como resultado, isso terá o efeito oposto e aumentará a probabilidade de se chegar a soluções estáveis. A formação de coalizões deveria ser pensada em termos de jogos de múltiplos níveis, sendo um jogo (de formação de coalizões) inserido em outro, mais amplo.

Resumindo a discussão até o momento: o Dilema do Prisioneiro é uma maneira útil de pensar o problema do conflito e cooperação de classes ein situação inflacionária. Assume-se que, onde as condições para cooperação mútua estão presentes, todos

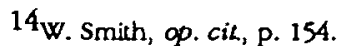

15 para uma breve discussão da literatura sobre os alinhamentos políticoeconômicos de grupos de empresários, ver I. Roxborough, "Unity and Diversity in Latin American History", Joumal of Latin American Studies, vol. 16, May 1984. 
os atores se beneficiam, diferentemente do que acontece se um deles deserta. O Dilema do Prisioneiro direciona nossa atenção para as estratégias adotadas pelos vários jogadores. Visto que o jogo é raraménte jogado, que a informação é imperfeita e que existe conhecimento mútuo das estratégias, a confiança deve ser mostrada pelos atores em um estágio inicial do jogo. O modelo do Dilema do Prisioneiro chama a atenção para as pré-condições sociológicas e políticas do pacto social como parte inerente da política antiinflacionária. Antes de indicar quais seriam essas précondições, examino o fracasso do pacto social no Brasil e seu relativo sucesso no México.

\section{PLANO CRUZADO}

O objetivo do Plano Cruzado brasileiro, implementado em 1986, era frear um processo diagnosticado como inflação inercial. $O$ argumento é simples: os agentes econômicos atuam supondo que os preços continuarão a aumentar porque essa tem sido a história do sistema. Com história pregressa de inflação persistente, os agentes econômicos desenvolvem expectativas inflacionárias, e por isso ajustam antecipadamente seu comportamento à inflação futura. Essa expectativa cria uma profecia que se auto-realiza. ${ }^{16}$

Os economistas que conceberam o plano Cruzado acreditaram poder eliminar as expectativas inflacionárias do sistema através de um pacote de medidas que incluía reforma monetária e congelamento de preços e salários por breve período de tempo. O congelamento não deveria ser muito longo, pois rapidamente os preços relativos se distorceriam.

O plano teve succsso inicial. A inflação caiu abruptamente de $17,6 \%$ ao mês, em fevereiro de 1986 , para menos de $1 \%$ nos meses seguintes. Como resultado, a renda real disponível dos assalariados cresceu, e esse aumento do poder aquisitivo se fez sentir através de um aumento de demanda de bens. Além disso, quem tinha poupança para fazer frente à inflação não sentiu mais

\footnotetext{
16 Um mecanismo comum para embutir expectativas inflacionárias no sistema, de maneira a reproduzir continuamente a inflação, é indexar preços futuros (inclusive salários) à inflação passada. Este é, entretanto, apenas um dos mecanismos concretos pelos quais as expectativas inflacionárias operam: indexar é uma das manifestaçōes do problema, não sendo necessariamente a questão central. A inflafão inercial é primariamente uma questão de expectativa.
} 
essa necessidade e começou a efetuar saques e gastar. O resultado dos dois fenômenos foi um aumento dramático na demanda de bens.

Os produtores responderam aumentando a produção mediante a diminuição da capacidade ociosa. O rápido crescimento da renda real tornou o plano Cruzado amplamente popular. Mesmo após seu colapso, pesquisas de opinião pública revelaram uma grande nostalgia pelo período de preços controlados. ${ }^{17}$ Entretanto, a produção rapidamente esbarrou nos limites da capacidade instalada e os novos investimentos foram insuficientes para aumentar a produção de maneira suficientemente rápida. As pressões inflacionárias começaram a se fazer sentir, ocorreu falta de produtos è começou a aparecer o mercado paralelo.

O Presidente Sarney, cuja popularidade crescera dramaticamente com a implantação do plano Cruzado, ${ }^{18}$ recusouse a considerar o abandono do controle de salários e preços, que foi mantido até depois das eleições para o Congresso e para os governos estaduais, em outubro de 1986. Nas eleições, o PMDB saiu-se muito bem: o plano Cruzado tinha assegurado dividendos eleitorais enormes.

Logo após as eleições, abandonou-se o controle de preços e salários, a inflação reprimida reapareceu, e pelo resto do mandato, José Sarney e seus ministros foram afligidos por inflação elevada ou hiperinflação. Sucessivos ministros da área econômica adotaram medidas de controle mais ou menos ortodoxas, empurrando. ą economia para a recessão sem eliminar a inflação.

$O$ resultado político foi o colapso da capacidade de governo, a cisão no PMDB, a queda vertiginosa da popularidade de Sarney e uma fragorosa derrota do PMDB nas eleições presidenciais de 1989 . Os dois partidos associados ao governo Sarney, o PMDB e o PFL, obtiveram respectivamente $4,4 \%$ e $0,8 \%$ dos votos no primeiro turno.

${ }^{17}$ Pesquisa de opiniāo realizada pela Data Folha em maio de 1987 perguntou aos entrevistados se eles tinham achado útil o controle de prę̧os e salários como mecanismo antiinflacionário. Não menos de $83 \%$ consideravam-no útil. Deve-se completar que $70 \%$ achavam que seria difícil conseguir controlar salários e preços. ${ }^{18}$ De acordo com pesquisa da Dataliolha, a popularidade de Sarney saltou de $33 \%$ (outubro de 1985) para um impressionante $82 \%$ (marfo de 1986). Com o fim do plano Cruzado, em novembro de 1986, sua popularidade caiu ao nivel prévio 34\%. Em maio de 1987, sua popularidade alcançou a igualmente impressionante marca de $8 \%$. 
Com o colapso dos partidos de centro, que antes pareciam consolidados, o segundo turno das eleições presidenciais foi disputado por dois candidatos anti-sistema, Lula, do Partido dos Trabalhadores, e um candidato relativamente outsider, Fernando Collor de Mello, cuja palavra de ordem na campanha foi a luta contra a corrupção. O voto se distribuiu igualmente entre ambos os candidatos e o presidente eleito, por pequena margem, Fernando Collor de Mello, teve de enfrentar a hiperinflação.

Desde 1986 discute-se intensamente as razões do fracasso do plano Cruzado. Existe concordância geral de que o pressuposto, implícito ou não, de que toda ou a maior parte da inflação brasileira era inercial, mostrou-se incorreto. Alguns elementos da inflação resultavam, sem dúvida, do desequilíbrio fiscal e evidentemente deveriam ter sido tomadas medidas para corrigí-lo. Ademais, rapidamente deveriam ter sido tomadas providências para conter parte da crescente demanda resultante de rendas mais altas e para assegurar a poupança pessoal. O aumento de impostos teria tanto aumentado a arrecadação do governo quanto reduzido a demanda de bens de consumo. Contudo, observar que erros foram cometidos quanto ao controle do déficit fiscal não implica que não existisse um componente inercial na inflação brasileira; isso significa apenas que o componente inercial não era o tinico fator que produzia inflação.

O plano Cruzado também foi excessivamente rígido na tentativa de congelar completamente os preços. ${ }^{19}$ Essa seria uma meta possível somente durante curto espaço de tempo. É claro que os arquitetos do plano pretendiam o congelamento de preços por tempo limitado, de modo que essa crítica pode ser considerada injusta. No curto prazo a meta de inflação zero teve um importante valor de choque para mudar as expestativas. Mas, como argumentarei a seguir, toda a abordagem do plano Cruzado para alterar as expectativas inflacionárias era equivocada. Uma política de salários e preços para ser confiável deveria ter sido mais flexivel.

Argumentou-se também que a continuação do congelamento resultou em desequilíbrio crescente dos preços relativos, o que é, sem dúvida, verdadeiro. Em um contexto de inflação crescente, congelar preços significa congelar preços em desequilibrio.

${ }^{19}$ R. Dornbusch, "Debt Problems and the World Macroeconom" in J. Sachs, (ed), Developing Country Debt and the World Economy, Chicago, University of Chicago Press, 1989. 
Com o tempo, em situação de rápido crescimento, os preços relativos tendem a tornar-se cada vez mais defasados. Portanto, o argumento para o retorno à flexibilidade de preços é forte. Mas isso somente funcionará se as expectativas inflacionárias tiverem sido efetivamente eliminadas do sistema. Os economistas brasileiros presumiram que o choque da reforma monetária e o congelamento de preços e salários surtiriam efeito rápidon, em um período inferior a 3 meses.

Não há, todavia, estudos econométricos sérios que meçam a velocidade com que as expectativas se ajustam às novas circunstâncias. Os responsáveis pelas políticas econômicas encontram-se portanto em terreno muito instável ao fazer qualquer projeção sobre a velocidade de ajuste de expectativas inflacionárias. Certamente seria razoável pensar que num país com longa história de inflação, numa situação de baixa credibilidade do governo e circunstâncias econômicas particularmente adversas, os agentes econômicos alterariam sua expectativa lentamente. Os responsáveis pelas políticas econômicas brasileiras superestimaram o efeito potencial do tratamento de choque.

Algumas inferências sobre expectativas inflacionárias, ainda que limitadas, podem ser feitas a partir de dados de opinião pública. Em maio de 1986, durante a vigência do plano Cruzado, o DataFolha perguntou a uma amostra da população o seguinte: "Por quanto tempo você acha que o governo deve manter o controle sobre preços e salários para acabar com a inflaçâo?" As respostas foram reveladoras. Doze por cento responderam que o controle deveria durar menos de 1 ano, $24 \%$ pensava que seria necessário 1 ano, $37 \%$ achava que seria necessário mais de 1 ano e $27 \%$ responderam "para sempre".

Esses dados sugerem que para a maioria da população brasileira os controles de preços e salários devem durar pelo menos 1 ano, e provavelmente muito mais, para trazer as expectativas inflacionárias a níveis razoáveis. O período necessário pode ser de 2 anos ou mais e seguramente não menos de 6 meses. Devemos confessar a ignorância sobre essa importante questão e tentar estudos empíricos. 20

20 Pode-se objetar que quando os economistas falam em mudar expectativas inflacionárias o que eles têm em mente nāo é a massa do grande público, mas alguns atores econômicos-chave: banqueiros, grandes investidores, etc. Esses agentes econômicos sofisticados respondem muito mais rapidamente à sinalizações do governo. Existe alguma validade nesse argumento. Entretanto, 
Se as expectativas inflacionárias se alteram lentamente, então o que está em jogo no combate da inflação inercial é o desenvolvimento de instituiçôes e não o tratamento de choque. Demasiada ênfase tem sido dada ao tratamento de choque nas discussões sobre políticas econômicas. ${ }^{21}$ O que é necessário, pelo menos para o tratamento do componente inercial da inflação, é o desenvolvimento de instituições para ação conjunta. Isso significa pensar o manejo das expectativas como processo semipermanente. 22

Uma maneira de lidar com expectativas é o governo anunciar que se absterá de usar medidas de choque e de introduzir mudanças inesperadas na política econômica. O segundo ministro da economia de Collor, Marcílio Marques Moreira, tentou, em julho de 1991, abordar dessa forma as expectativas. Uma maneira mais adequada, entretanto, de lidar com esșa questão, é através do uso de mecanismos corporativos de um ou outro tipo.

Instituições corporativas são compatíveis tanto com democracias quanto com regimes não-democráticos, e são freqüentes nos sistemas políticos das democracias sociais da Europa Ocidental, assim como na América Latina. Sua forma clássica é um conselho tripartite (com representantes do Estado, associações de empregadores e sindicatos) com poder de regular

mesmo que os agentes mais importantes assumam a liderança na sinalização de novas regras do jogo para o resto da economia, ainda assim será necessário estimar o atraso com que os demais agentes econômicos os acompanharão. Devese aqui considerar, por um lado, a massa de atacadistas e pequenos comerciantes e empresários e, por outro, os sindicatos.

21 As razōes para isso não são dificeis de encontrar. A inabilidade dos governos em desenvolver instituiçōes viáveis para ações conjuntas contra a inflação, juntamente com a falta de gosto e confianfa dos tecnocratas pelo processo político, os predispõe a buscar soluçōes que pareçam estar inteiramente sob o controle do governo. O planejamento secreto dos planos Austral e Cruzado e a crença de que poderiam ser efetivamente impostos à sociedade por um Estado tecnocrático são exemplos claros dessa atitude. Desnecessário dizer que o argumento defendido nesse trabalho postula que essa é uma atitude contraproducente para o processo político.

22 Uso a expressão semipermanente para indicar um sistema no qual o uso do controle de preços e salários é visto como um aspecto normal de política pública. Podem haver periodos em que o controle de pref̧os e salărios não seja usado, sendo os pref̧os (e salários) definidos exclusivamente pelo mercado ou, mais precisamente ${ }_{3}$ sem acordo prévio entre os agentes e o governo. Entretanto, se a inflafão escapar do controle, neste tipo de sistema político haverá tendência de se usar mecanismos institucionais para o controle de pref̧os e salários. 
políticas econômicas (especialmente industriais), retirando do controle direto do Parlamento muitas das decisões nessa área. ${ }^{23}$

Tais instituições corporativas envolvem pactos ou acordos explícitos ${ }^{24}$ que asseguram importantes dividendos econômicos e políticos. Eles legitimam as políticas de governo e proporcionam um quadro estável para a administração política.

Muitos governos sabem da utilidàde de pactos formais. O governo Sarney, por exemplo, tentou articular um pacto com empresários e sindicatos em torno das políticas anti-inflacionárias. Em 1985, durante vários meses, Sarney realizou esforços repetidos para persuadir empresários e sindicatos a se unirem em um pacto formal; esses esforços malograram por uma série de razões discutidas a seguir. O governo Collor de Mello também tentou, por duas vezes, organizar um pacto social com sindicatos e empregadores. Até o momento, entretanto, não obteve sucesso nas suas tentativas, possivelmente pela ausência de compromisso sério com esse tipo de solução para a inflação.

\section{O PLANO CRUZADO COMO SUBSTITUTO DO PACTO SOCIAL}

Embora o plano Cruzado corporificasse muitos dos aspectos de uma abordagem do tipo pacto social, dela diferia por uma série de aspectos centrais. O plano foi imposto pelo governo sem a concordância explícita dos atores sociais mais importantes, e muitos de seus pressupostos baseavam-se no tratamento de choque da inflação. Além de um sem número de falhas econômicas e técnicas, o plano Cruzado foi prejudicado pela indecisão do governo, pelo uso inepto de incentivos para obter o apoio dos trabalhadores e pela hostilidade dos sindicatos. Desde o início era evidente a falta de coragem ou, para ser mais preciso, a divergência fundamental no governo quanto ao seu empenho

\footnotetext{
23 Existe atualmente uma enorme literatura sobre o corporativismo, tanto na Europa quanto na América Latina. Em termos gerais, considero muito útil a discussão de A. Przeworski, Capilalism and Social Democracy, Cambridge, Cambridge University Press, 1985.

${ }^{24}$ Não é infreqüente se falar sobre acordos ou pactos capital-trabalho como fenômenos implícitos. Isto é, quando os vários atores se comportam como se todos soubessem e concordassem com as "regras do jogo" e tivessem chegado a entendimentos tácitos. Quero distinguir esse uso da noção de "pacto" do sentido em que usei a palavra neste artigo. Aqui refiro-me exclusivamente a pactos formais, explícitos.
} 
em efetivar o pacto social. O ministro do Trabalho, Almir Pazzianotto, era o seu principal proponente. O compromisso do Presidente Sarney com o pacto parecia meramente retórico. Menos interessados estavam o ministro da Justiça, o ministro da Economia, Dilson Funaro, e outros membros da equipe econômica. Como resultado o governo dava sinais contraditórios às organizações dos trabalhadores. Ao mesmo tempo em que se adotava uma série de medidas em favor dos trabalhadores, algumas greves importantes foram reprimidas pelos militares.

O governo também falhou no uso efetivo de possiveis incentivos. Com o plano Cruzado já em operação, o governo perdeu seu maior trunfo: o aumento real do poder aquisitivo dos assalariados resultante do congelamento de preços. Não obstante, havia outros incentivos a serem oferecidos: uma atitude mais liberal e moderada do governo em relação à intervenção do Estado nos sindicatos e uma reforma da legislação trabalhista (ou uma aplicação seletiva da legislação vigente) que fosse mais favorável aos sindicatos.

Evidenciava-se aí a falta de coordenação da estratégia do governo. O ministro do Trabalho, Pazzianotto, interrompeu, de fato, as intervenções ministeriais nos sindicatos e, de maneira geral, agia de modo a favorecê-los. Ironicamente, sua postura prótrabalho significou que outro possivel trunfo que o governo poderia ter oferecido aos sindicatos na negociação do pacto social já tinha sido usado. Uma estratégia mais astuta seria a de condicionar o apoio do Ministério do Trabalho aos sindicatos a um compromisso destes a engajar-se num pacto social.

Uma outra vantagem. que o governo poderia ter oferecido aos sindicatos em troca de sua cooperação no pacto social, a reforma da legislação trabalhista, já não mais estava sob seu controle. A convocação da Assembléia Constituinte tirou das mãos do presidente a iniciativa de realizar reformas na Constituição. Apesar disso, dada a predominância dos partidos do governo, PMDB e PFL, na Assembléia Constituinte, teria sido possivel amarrar as mudanças da legislação trabalhista à cooperação dos sindicatos, apresentando as reformas legislativas e constitucionais como uma oferta do governo.

$\mathrm{Na}$ verdade o processo de reescrever a Constituição estendeu-se muito e o governo perdeu o controle sobre ele. Além de prolongar o impasse político e a estagnação, com efeitos deletérios sobre o sistema político como um todo, a perda da 
iniciativa governamental com relação às reformas da legislação trabalhista significou que ele perdera mais um dos trunfos que poderia ter oferecido aos sindicatos.

Em resumo, o governo podia oferecer pouco aos sindicatos em troca da sua adesão ao pacto social. A maioria dos incentivos disponíveis já tinha sido oferecida ou tinha escapado do controle do governo. Não é de surpreender que os apelos de Sarney para o estabelecimento do pacto social tenham se tornado crescentemente retóricos. A medida da bancarrota política dos apelos do governo para o estabelecimento do pacto social é o fato de que, como já comentei 25 , eles geralmente seguiam-se ao aumento das atividades grevistas.

Nos primeiros dias da presidência de Collor foram feitos esforços para forjar um pacto social. Um grupo de empresários que advogava ação mais ativa, o $\mathrm{PNBE}^{26}$, mantinha boas relações com a CUT e organizou encontros para a discussão dessa possibilidade. Esse primeiro esforço, entretanto, fracassou, principalmente porque, ao que parece, faltou entusiasmo por parte do governo.

O programa ortodoxo de estabilização, associado ao início de um esforço aparentemente sério de instituir reformas estruturais, teve o efeito imediato de mergulhar a economia na recessão. Defrontado com a resistência à recessão profunda, tanto por parte dos empresários quanto dos sindicatos, o governo Collor foi incapaz de derrotar a inflação com medidas puramente ortodoxas. No fim de 90 a inflação mensal era de 19\%. Nesse momento, Collor voltou-se mais uma vez para o pacto social, novamente sem sucesso.

Por estranho que pareça, as probabilidades de realização de um pacto social entre empresários e sindicatos eram maiores do que entre qualquer um des'ses dois grupos e o governo. A despeito de uma longa história de corporativismo, nem os sindicatos nem os empresários confiavam na administração de Collor, como não confiavam na de Sarney.

De fato, a associação entre o corporativismo como sistema de controle do trabalho e a ditadura militar repressiva

\footnotetext{
25 I. Roxborough, op. cit., in B. Stallings and R. Kaufman (eds.), Debt and Democracy in Latin American, op. cit.

260 Pensamento Nacional das Bases Empresariais é formado por empresários insatisfeitos com a política da principal organização de empregadores, a Federação de Indústrias do Estar", de São Paulo, Fis:SP.
} 
levou muitos empregadores e sindicalistas a rejeitar toda e qualquer instituição corporativa. Por outro lado, apesar de história recente de conflito intenso, os sindicatos e os empregadores se respeitavam e haviam aprendido a conviver entre si.

Para resumir a experiência brasileira, o fracasso da política antiinflacionária deve-se, em parte, a que se concentrou exageradamente num aspecto da inflação (a inércia), negligenciando outros fatores. Houve evidente fracasso político na adoção de medidas necessárias para controlar o déficit fiscal. A imposição de rígida política de controle de preços e salários, ao invés do desenvolvimento de uma política de preços e rendas por meio de um pacto social, também pesou bastante no fracasso. A tentativa de tratar a inflação inercial através da imposição tecnocrática foi uma política de curto prazo que ignorou totalmente a necessidade de construir mecanismos corporativos funcionais para uma "luta de classes democrática". Em resumo, não houve esforço no sentido da construção de instituições. O resultado foi o declínio econômico e político, apesar do apoio maciço e contínuo para uma política de preços e salários.

\section{A EXPERIÊNCIA MEXICANA}

Em 1987 foi instituída no México uma política de controle de salários e preços. Conhecida inicialmente como Pacto de Solidariedad Económica, foi posteriormente chamada de Pacto de Estabilidad y Crecimiento Económico (PECE). Por ocasião de sua introdução em 1987, a inflação alcançara índice anual de $160 \%$, chegando a $14,8 \%$ em dezembro de 1987 . A partir de fevereiro de 88 , a inflação começou a cair abruptamente, alcançando $114 \%$ em $1988,20 \%$, em 89 e $30 \%$, em 90 . Por quase três anos a inflação tem sido mantida em níveis controláveis. Índices de 20 e $30 \%$ são altos o suficiente para causarem preocupação, e o risco de que a inflação se acclere novamente permanece, mas o contraste com o Brasil é marcante. Embora a inflação anual de 20 a $30 \%$ seja muito maior do que os $3,8 \%$ da década dos $60^{27}$, é menor que a inflação registrada entre 1982 e 1987.

${ }^{27}$ E. Buffie e A. Sanjines Krauze, "Mexico 1958-86: From Stabilizing Development to the Debt Crisis" in J. Sachs (ed), op. cit. 
Por que o Governo Mexicano foi (relativamente) bemsucedido em manter a inflação em níveis razoáveis ? São seis as razōes principais.

Em primeiro lugar, o governo Salinas implantou uma estratégia anti-inflacionária que abarcava os vários componentes da inflação e não apenas um; manteve. uma política fiscal e monetária cautelosa e implementou o programa de reformas estruturais iniciado pela administração de de la Madrid, com o objetivo de abrir a economia mexicana. O ingresso no GATT, o programa de privatização e as propostas de acordo comercial com os Estados Unidos são componentes importantes do pacote de reformas estruturais destinadas a reduzir as imperfeições de mercado. Um dos resultados deste equilibrado pacote de medidas foi que o superaquecimento da economia, freqüentemente associado a políticas heterodoxas, não ocorreu.

O segundo fator diz respeito à confiança no governo e à sua credibilidade. Em grande parte isso se deve à percepção, por parte dos investidores, de que o México é um país politicamente estável. O PRI nunca perdeu uma eleição presidencial e muito provavelmente produzirá o novo presidente em $1994 .{ }^{28}$ A consistência e coerência (ao longo do tempo) das políticas de governo está estreitamente ligada ao domínio da política mexicana pelo PRI. A série de reformas econômicas neoliberais (a entrada no GATT e o Acordo de Livre Comércio com os Estados Unidos) aumentaram a confiança dos investidores. O governo também adotou conscientemente a tática de bom comportamento quanto ao pagamento da divida externa, obtendo uma considerável redução de débito. As medidas para atrair de volta o capital que se evadira do México, somadas à dimiução da dívida, fortaleceram muito a confiança internacional e doméstica na política econômica de Salinas, e esse incremento de confiança teve efeitos positivos sobre o fluxo de capital e conseqüentemente sobre a inflação.

Em terceiro lugar, a política anti-inflacionária mexicana caracterizou-se por um pacto social explícito e formal, assinado por periodos de tempo finitos, geralmente seis meses. À medida que se aproxima a época de sua renovação, os signatários se engajam em manobras públicas na tentativa de influenciar os termos do próximo pacto. Geralmente ameaçam não assinar o

28 E questionável o quanto esta percep̧̧ão de estabilidade poítica é real. 
novo pacto a menos que se alcance um acordo favorável. Por trás do jogo de cena se desenvolve um processo real de renegociação periódica, que o impede de se tornar letra morta 29.

Além da renegociação periódica do pacto, há uma Comisión de Seguimiento y Evaluación del Pacto que se reúne regularmente cada uma ou duas semanas para discutir os preços relativos. Além de vigiar os preços, a Comisión acompanha o fornecimento de produtos ao mercado, na tentativa de detectar precocemente a falta iminente de gêneros. Há também comissões técnicas encarregadas de várias tarefas. A Comisión proporciona coerência microeconômica para o pacto macro-econômico.

Embora a iniciativa do pacto tenha sido do governo, é importante distinguí-lo claramente da imposição unilateral das políticas de choque do plano Cruzado brasileiro e do plano Austral argentino. Evidentemente os sindicatos e, em menor grau, as associações de empresários dependem consideravelmente do governo não podendo comportar-se como agentes inteiramente autônomos.

Segundo Augusto Bolívar, a primeira versão do pacto foi simplesmente imposta pelo governo apesar da profunda desconfiança por parte dos sindicatos ${ }^{30}$. O fato do pacto ter sido imposto talvez indique importante semelhança com a situação brasileira. Seria errôneo, porém, exagerar a medida em que os sindicatos e associações de empresários mexicanos são meros títeres do Estado. É mais exato afirmar que sindicatos e associações de empregadores são entidades independentes com longa história de colaboração com o Estado e uma percepção bastante clara dos custos do confronto com ele. ${ }^{31}$ A longa história de acordos corporativos predispõe sindicatos e empresários a cooperar entre si e com o Estado.

\footnotetext{
${ }^{29}$ Alguns têm argumentado que os acordos alcançados pelo pacto são acordos de elite e não têm incluído as bases. Isto é verdade, e dificilmente poderia ser de outra forma.

30 A. Bolivar, "El periodo de transiciones a la modernidad" in R. Garavito and A. Bolivar (eds), op. cil., p. 54-7.

31 Isso não impede que eles se confrontem ocasionalmente com o governo. Por exemplo, as associaçōes de empresários foram, no geral, hostis ao presidente Echeverria, e mesmo sindicatos tão moderados quanto o CTM tiveram confrontos com o governo, como aconteceu no inicio da administração de de la Madrid. (Ver I. Roxborough "The Economic Crisis and the Labor Movement" in G. Philip (ed.) The Mexican Economy, London, Roulledge, 1988.
} 
Isso nos conduz à quarta característica da política antiinflacionária mexicana: o PECE foi implementado por meio de organizaçōes intermediárias. Tanto sindicatos quanto associaçōes de empregadores tiveram papel importante na vigilância do pacto e na contenção dos filiados mais impacientes. O México apresenta nível relativamente alto de sindicalização; os sindicatos são bem organizados, unindo-se numa estrutura em forma de pirâmide. Cerca de $90 \%$ dos sindicatos e sindicalizados são filiados ao Congreso del Trabajo, que apóia o governo. Esses sindicatos adotam historicamente uma estratégia de colaboração estreita com o governo. Em troca, líderes sindicais são nomeados para cargos políticos e recebem o apoio do governo. Esta aliança histórica é sutil. Às vezes, alguns sindicatos demonstram certo grau de independência; em outros momentos, o governo exige (e consegue) apoio incondicional.

Há no México grande variação quanto às relações entre empregadores e sindicatos. Alguns sindicatos são fíctícios, operando "contratos de proteção", isto $\varepsilon$, o sindicato existe apenas nominalmente, para impedir o surgimento de uma organização autônoma de operários. Alguns líderes sindicais negociam contratos sem nenhuma consulta às bases e é de conhecimento geral que a corrupção não é infreqüente. Entretanto, nos sindicatos maiores, e no setor moderno da economia, a negociação coletiva é genuina e a democracia sindical ou revolta das bases é uma possibilidade. Como resultado, a pressão das bases impõe restrições às concessões que os líderes sindicais possam fazer tanto ao governo como aos empresários. Para se compreender o sindicalismo mexicano é necessário encontrar o ponto certo de equilíbrio entre uma visão dominada pelos oligarcas sindicais corruptos, que apóiam o governo incondicionalmente, por um lado, e a negociação coletiva genuína, por outro.

O empresariado teve papel chave no pacto. Por trás do pacto formal houve um outro, implícito e possivelmente mais importante, entre governo e empresários. Baseando-se em longa história de acordos corporativos, o governo se reúne regular e informalmente com os principais empresários para discutir políticas adequadas de preços. A partir daí essas empresas vigiam os preços no seu setor. De certa forma, esses arranjos informais entre grandes empresas e governo são o verdadeiro pacto social no México contemporâneo. Seria entretanto um erro grave de julgamento deduzir a partir daí que o pacto formal incorporado 
no PECE não é importante. Pelo contrário, sem isso as negociações informais entre governo e grandes empresas não seriam possiveis.

A quinta peculiaridade da política anti-inflacionária mexicana, tal como corporificada pelo PECE, é seu caráter semipermanente Não se trata de um choque temporário, trata-se, pelo contrário, de arranjos institucionais que são percebidos como duradouros. Mesmo que se abandone o PECE, a maioria dos atores econômicos no México sabe que uma maneira semelhante de controle de salários e preços pode ser restabelecida no futuro. O caráter semipermanente do PECE é importante tanto na redução das expectativas inflacionárias como porque permite aos vários atores perceber que, se não se saírem muito bem em determinada rodada de negociações, podem ser melhor sucedidos nas rodadas subseqüentes.

Finalmente, o governo não tentou alcançar inflação zero. Em vez de congelamento de salários e preços, instituiu controle de salários e preços, permitindo flexibilidade muito maior na resposta a desequilíbrios de curto prazo. Entretanto, essa mesma flexibilidade contribuiu para manter um certo.nível de expectativas inflacionárias. No processo, o PECE foi muito mais bemsucedido no controle de salários do que no nível gera! de preços. Os salários reais continuaram a cair, acarretando naturalmente críticas dos sindicalistas. Entretanto, a maioria deles via o PECE como mal menor e, embora o plano significasse diminuição dos salários reais, os sindicalistas acreditavam que sem ele a inflação acelerar-se-ia e os salários reais cairiam ainda mais rapidamente.

Os empresários tinham opiniōes contraditórias sobre o PECE. Alguns achavam que deveriam opor-se, por princípio, a qualquer controle de preços e pressionaram para que o controle de preços terminasse logo. Outros viam o PECE como parte importante da estratégia antiinflacionária e, à medida que a estratégia permanecia coerente, apoiavam-na: $\mathrm{O}$ apoio duradouro do empresariado dependerá, em parte, da persistente coerência da política do governo; dependerá, especialmente, de como se comportarão os gastos do governo no período que antecederá as eleições de congressistas e governadores em 1991. Se Salinas acompanhar o ciclo político-econômico normal de gastos governamentais, aumentando-os no periodo pré-eleitoral, é provável que perca o apoio dos principais empresários, que interpretarão esse comportamento como uma volta ao "populismo". 


\section{PONTOS CRÍTICOS DA POLÍTICA ANTI- INFLACIONÁRIA MEXICANA}

Têm havido apelos, especialmente nos círculos empresariais, para o fim da política de controle de salários e preços. Com a iminente assinatura do acordo de livre comércio entre México e Estados Unidos, alguns argumentaram que o controle de preços e salários é incompatível com uma economia aberta. Existe, ademais, uma crença bastante disseminada de que o controle de preços e salários, por sua própria natureza, é uma medida temporária, e que os agentes econômicos deveriam se preparar para "aterrissar" em um mercado livre.

Os sindicalistas também se queixaram de que o PECE permitiu um aumento mais rápido dos preços do que dos salários nominais. Apesar disso, a maioria dos líderes sindicais concordará em que, apesar da defasagem dos salários, sua situação poderia ser pior sem o PECE. Um líder afirmou que qualquer tentativa de abandonar o PECE seria "suicida" 32 .

\section{DOIS JOGOS SIMULTÂNEOS}

A maior dúvida talvez resida no fato de que a formulação de políticas anti-inflacionárias envolve dois jogos simultâneos, um interno e outro externo. Até aqui, a ênfase recaiu no jogo do Dilema do Prisioneiro entre sindicatos, associações de empresários e governo, isto é, no jogo interno. Entretanto, como se apontou acima, qualquer estratégia anti-inflacionária e de crescimento baseada (pelo menos parcialmente) em financiamento externo (seja na forma de novos fluxos de capital, seja pela redução da saída de capitais como parcelas de pagamento da dívida externa ou fuga de capitais) implica que o governo participe de um segundo jogo, desta vez com investidores externos. O ponto importante aqui, como enfatizou Guillermo O'Donnell, é que a necessidade de gerar confiança entre investidores externos força o governo a adotar medidas altamente ortodoxas, ainda que seja só para sinalizar-lhes que os riscos que correrão serão mínimos.

32Entrevistado pelo autor, 14-1-1991. 
Normalmente, os investidores externos veriam com bastante suspeita um programa anti-inflacionário com componentes heterodoxos. No caso mexicano, contudo, eles parecem ter engolido o amargo remédio sem muitas queixas. Pode-se supor que suas razōes tenham a ver com a crença de que o governo mexicano está irrevogavelmente comprometido com a ortodoxia fiscal e com um programa sério de reformas estruturais, e com a crença de que haverá estabilidade política num futuro previsivel.

O que permanece obscuro é a duração do controle de salários e preços, que os responsáveis pelas políticas mexicanas acreditavam ser necessária para reduzir a inflação inercial. Por ocasiāo da redação deste trabalho, havia grande otimismo sobre o comportamento futuro da economia mexicana, atribuivel sobretudo à iminente instituição do Acordo de Livre Comércio com os Estados Unidos. O governo sinalizara uma meta pela qual a inflação de 1991 deveria ser a metade da de 1990, sugerindo poucas mudanças na inflação mexicana durante 1991. Embora Salinas tenha dado sua aprovação para uma eventual ampliação do PECE, muitos comentaristas sugeriram que, com a entrada do México num acordo de livre comércio com os Estados Unidos, o controle de preços e salários não mais seria apropriado. Embora não pareça ser esse o caso de um ponto de vista estritamente lógico, é evidente que as pressões para a liberalização do comércio operam contra o uso contínuo de instrumentos heterodoxos.

Devido à simultaneidade dos jogos interno e externo que o governo mexicano deve jogar e a importância que os investidores externos atribuem à estabilidade política no país, a manutenção da confiança do investidor provavelmente será incompatível, no México, com a transição democrática. Pode ser que no futuro seja necessário escolher entre metas políticas e econômicas. A permanência do México como um dos poucos países não-democráticos do continente pode ser o custo a ser pago pela recuperação da economia e pelo controle duradouro da inflação.

Em resumo, enquanto o México têm as instituições corporativistas de um tipo que possibilitam uma solução ótima para o Dilema do Prisioneiro, a manutenção dessa solução pode ser extremamente dificil devido às pressões externas. Isso acarreta incertezas sobre a transição para a democracia. $\hat{E}$ evidente que a estratégia do PRI é tentar vencer genuinamente as eleições 
presidenciais de 1994. Sem dúvida o partido espera alcançar a vitória de três maneiras:

1. pela reativação da economia e pelo controle duradouro da inflação, levando a um nivel de aprovação do desempenho do governo suficiente para manter o nivel de sustentação eleitoral; lismo e controle;

2. pelo uso contínuo das formas tradicionais de cliente-

3. pelos ataques sistemáticos ao PRD (oposição), de forma a que esse partido não repita seu impressionante desempenho eleitoral de 1988. Pode-se imaginar que essa estratégia funcionará e que em 1994 o México se torne uma democracia com o PRI ainda no poder. Mas este é um cenário extremamente otimista; podem-se levantar sérias dúvidas sobre o futuro da democracia no México.

No Brasil e na maioria dos países latino-americanos a democracia não parece estar diretamente ameaçada, pelo menos no futuro imediato. Seu problema é o inverso do mexicano: eles têm de criar instituições corporativas que viabilizem os pactos sociais e que possibilitem a eliminação da inflação inercial sem incorrer nos altos custos inerentes à execução de políticas exclusivamente neoliberais. O México possui, pelo menos em forma embrionária, as instituições mas não a democracia; o Brasil tem a democracia mas não as instituições necessárias.

\section{A QUESTÃO DO CORPORATIVISMO}

Argumentei que o controle bem-sucedido da inflação inercial requer um pacto social explícito e a criação de estruturas institucionais para mediar conflitos de classe e conflitos setoriais com respeito às políticas macro-econômicas. Nas socialdemocracias da Europa Ocidental, as instituições que tiveram essẻ papel são geralmente descritas como "corporativistas": organizações tripartites para o planejamento econômico e a regulação dos conflitos. $\mathrm{Na}$ presente conjuntura, entretanto, o corporativismo é amplamente rejeitado na América Latina como forma institucional.

A rejeição do corporativismo se dá em dois planos. Em primeiro lugar, as ideologias neoliberais sugerem que a interferência no mercado deve ser minima. A segunda linha de ataque vem da esquerda e do movimento sindical, que identificam o 
corporativismo aos sistemas de controle sindical, típicos do Estado Novo e do governo militar de 1964-85 no Brasil, e à liderança sindical conservadora e intervenção nos sindicatos no México, geralmente chamadas "charrismo". Em ambos os países, a tentativa de assegurar a independência dos sindicatos em relação ao Estado levou a uma oposição frontal ao corporativismo como sistema de regulação de conflitos. O perigo está em que a esquerda e as organizações sindicais simplesmente repitam a crítica à intervenção do Estado na regulação do mercado feita pelos neoliberais.

A esquerda no Brasil e no México errou o alvo. O corporativismo, enquanto tal, não é o culpado. Sistemas tripartites de regulação de conflito são, em princípio, neutros quanto às classes. O favorecimento de uma ou outra classe ou o atrelamento a um projeto específico do Estado depende do poder e de recursos de cada um dos atores e das estratégias usadas 33 .

Tanto no Brasil quanto no México, os sindicatos são potencialmente bastante poderosos, tanto econômica quanto eleitoralmente. O problema do corporativismo tal como praticado nesses países é que a liderança sindical tem sido cooptada ou controlada pelo Estado. Ou seja, enquanto os arranjos corporativistas da social-democracia européia expressaram (pelo menos formalmente) acordos entre atores autônomos, na América Latina o corporativismo, tal como o conhecemos, envolve acordos com os trabalhadores organizados de forma heterônoma. Os trabalhadores nào tiveram lideranças autênticas, portanto, não propuseram políticas tão favoráveis quanto possível para a sua classe. Em conseqüência, as esquerdas brasileira e mexicana rejeitaram tudo o que se relacionava $\mathrm{com}$ as velhas práticas, jogando fora o bebê junto com a água do banho.

Para que o pacto social na América Latina funcione, os sindicatos devem aceitar a necessidade de formas semi-permanentes de compromisso de classe. Para que isso produza os melhores resultados para as classes trabalhadoras, as organizações trabalhistas devem representar autenticamente seus membros.

33 Pode-se objetar que, em uma economia capitalista, os trabalhadores sempre serão o parceiro mais fraco, e que portanto as instituições corporativistas sempre favorecerão os capitalistas. Dois pontos devem ser ressaltados: em primeiro lugar, isso não é sempre verdade; em segundo lugar, mesmo que seja verdade, o argumento se aplica a todas as formas instituciona is de conflito de classes, tanto a formas não-corporativistas quanto às corporativistas. Não pode ponanto ser usado como argumento contra corporativismo. 
Sem sindicatos democráticos, uma estrutura sindical unida e coerente e partidos políticos que representem genuinamente os interesses dos trabalhadores, o corporativismo não levará aos mesmos tipos de resultados obtidos pelas social-democracias da Europa Ocidental. Corporativismo mais democracia é igual à democracia social.

Movimento nessa direção implica em reavaliação e não em abandono completo do corporativismo. A construção institucional desse tipo deve caminhar pari-passu com a manutenção e ampliação de reformas estruturais neoliberais para melhorar a eficiência da economia. O que pode se desenvolver é uma forma de "liberalismo implantado" - políticas econômicas liberais em algumas áreas da economia sustentadas por instituiçôes corporativistas em outras áreas. Este tipo de ordem institucional não é uma utopia, embora se confronte com dificuldades sérias derivadas da necessidade de jogar simultaneamente os jogos interno e externo. É difícil, embora não impossível, preencher os critérios para soluções ótimas em ambos os jogos simultaneamente. À medida que paises latino-americanos sejam capazes de caminhar na direção desse tipo de ordem institucional, será possível reconciliar crescimento econômico, controle da inflação e democracia (relativamente) estável.

Tanto o Brasil quanto o México têm uma longa herança de instituições corporativistas. Infelizmente, aos olhos da classe trabalhadora organizada e da esquerda, elas estão manchadas com as estratégias repressivas dos regimes autoritários. À medida que Brasil e México caminhem na direção da democracia, tanto no nível das políticas nacionais quanto no da criação de partidos e organizações intermediárias que genuinamente representem suas bases, a esquerda deverá reavaliar sua crítica ao corporativismo. Somente assumindo e transformando as instituiçōes corporativistas é que a emergente democracia na América Latina poderá se transformar na social-democracia.

A única alternativa é o triunfo contínuo do neoliberalismo. Nada mais está na agenda.

IAN ROXBOROUGH é professor do Departamento de Sociologia e Historia da State Universily de Nova York e foi pesquisador-visitante no CEDEC. 